einer Besprehuñg wärdigte und Zweifel an der Richtigkeit meiner Beabachtungen aussprechen konnte.

Diese Discussion vermuthlich veranlasste Hanse mann zu InjectionsVersuchen, mit welchen er mehr Glück hatte, als ich einige Jahre zuvor. Es gelang ihm, die Poren-Canäle in schönster Weise bei normalen Thieren mit Hülfe der von Hermann ${ }^{1}$ ) angegebenen Methode zu injiciren und damit auf experimentellem Wege die Thatsache zu beweisen, die G. Hauser auf Grund seiner mikroskopischen Bilder schon postulirt hatte.

Aus der Einleitung zu Hansemann's Arbeit und aus seinen Worten in dem oben citirten Vortrage erhellt obne Weiteres, dass er keinen A ugenblick daran dachte, mir die Priorität dieser Entdeckung streitig zu machen.

Demgegenüber muss es befremden, wenn sein Schüler Sudsukizu einer so abweichenden Auffassung der Verhältnisse koumt. Ich will mich dabei, dass er meine Arbeit und ebenso die Arbeiten Hauser's ganz und gar unerwähnt lässt, nicht aufhalten und eine Erklärung dafür suchen, dass er Hansemann als den Entdecker der normalen Poren-Canäle schlankweg bezeichnen zu dürfen glaubt. Hierfür ist, wie mir scheint; eine gewisse Unklarheit der Auffassung verantwortlich zu machen.

Denn die Thatsache des Vorbaudenseins dieser Canälchen in der menschlichen Lunge. wurde von mir festgestellt. Die Frage, ab sie nur in der erkrankten, oder auch in der normalen Lunge vorhanden.seien, liess ich offen, ohne mich für die eine oder die andere Eventualität zu entscheiden. Schon G. Hauser konnte sie mit Bestimmtheit für normale Gebilde erklären, und $\mathrm{H}$ ansemann hat das Verdienst, für diese Auffassung den experimentellen Beweis am Thiere erbracht und damit die letzten $Z$ weifel beseitigt $z u$ haben. Ich bin absichtlich nicht auf den materiellen Theil der Arbeit Sudsuki's eingegangen; ich hoffe, dies später thun zu können.

\title{
2.
}

Einige Bemerkungen zu dem Aufsatze von Dr. Freudweiler, ,über einen Fall von multiplen Gliomen des Rückenmarkes"

\author{
in diesem Archiv (Bd. 158, Heft i) \\ ron \\ Prof. Fr. Schultze \\ in Bonn.
}

Der eigenthümliche Fall von multipler Lochbildung im Rückenmarke, welcher kürzlich aw angegebenen Orte von Herrn Dr. Froudweiler ver-

I) Pflüger's Areh., XX. 
öfentlicht worden ist, erinnerte mich, als ich der zugebörigen Abbildungen ansichtig wurde, sofort an einen äbnlichen Fund, den ich schon vor einer Reihe von Jahren in Heidelberg machte. Ich musste ihn allerdings ganz anders auffassen, als Berr Dr. Freudweiler in seinem Falle gethan hat, nehmlich als ein Kunstproduct.

Ich glaube, dass von vorn herein wohl jeder, der viele anatomische Untersuchungen des Nervensystems angestellt und speciell Gliome, sklerotische und Erweichungs-Heerde in grosser Anzahl studirt hat, zu der Meinung gelangen muss, dass sich die von Freudweiler beschriebenen Veränderungen in erheblicher Woise von irgend welchen bisher bekannten pathologisehen Processen unterscheiden. Besonders auffallend ist es, dass sich um die beschriebenen Substanz-Verluste herum keine andere Veränderungen vorfanden, als "wie comprimirt" oder „etwas dichter gefügt" erscheinende Gewebs-Partien. Nichts von Quellungen der Axencylinder, wie bei acuten Erweichungs- und Entzündungs-Processen, nichts von Kernvermebrungen an den Gefässen, in der Glia, nichts von Körnchenzellen, wie bei etwas älteren krankhaften Veränderungen, war zu bemerken.

Allerdings stellten manche der Freudweiler'schen Heerde keine vollständig leeren Hohlräume, sondern hellgefärbte, mehr durchsicbtige Partien dar, die nach der Beschreibung und nach den Bildern aucb noch Axencylinder und "vollkommen normale" Gefäss-Querschnitte" enthielten.

Nun, ich habe ein ganz ähnliches Verhalten von vollkommener und unvollkommener derartiger Lochbildung einmal in einem Räckenmarke gesehen, das zufällig im winterkalten, ungeheizten Zimmer längere, unbestimmbare Zeit hindurch in der Müller'schen Flüssigkeit eingefroren gewesen und nachber von mir wieder anfgethaut worden war. Das Präparat warde mir durch diese unfreiwillige Erfrierung und Aufthaung zwar sonst unbrauchbar, belehrte mich aber, dass auf die genannte Weise ein gewisser „Etat cribiè ${ }^{\prime}$ entstehen kann, dessen wirkliche praenortale Existenz mir seitdem stets zweifelhaft geblieben ist, obgleich er als ein pathologischer Befund im Gehirne mebrfach früher beschrieben worden ist.

Im Hinblicke auf diesen Fund und aus andern Gründen, um überbaupt die Folgezustände versehiedener Behandlungsarten des Rückenmarkes kennen zu lernen, habe ich eine Zeit lang auch künstlich Nerven-Substanz eintrocknen und faulen lassen, und sie dann gehärtet und Querschnitte angelegt, bin aber solchen Lochbildungen dabei nicht begegnet, die man wieder in anderer Form bei sehr alt gewordenen Alcohol-Präparaten finden kann. Ob man nicht bei umfangreicheren Modificationen der Fintrocknungs- und Fäulniss-Versuche, wie ich sie seinerzeit vorgenommen habe, doch manchmal solche arteficiellen Substanz-Verluste vorfinden wird, muss ich dahingestellt sein lassen. In dem erwähnten durchfrorenen Rückenmarke war vor der Vereisung desselben nichts von den Lacunen wahrnehmbar gewesen, die sich später zu meiner unangenebmen Ueberraschung vorfanden.

Es gebt natürlich bei einem derartig berbeigeführten Processe kein Ge- 
webe verloren, sondern es wird nur theilweise gelockert und zerrissen, und retrahirt sich dabei in unregelmässiger Weise rings um die entstehenden Löcher, so dass sich das Erscheinen von dichter gefügtem Gewebe in der Umgebung derselben und das Freibleiben von jeder Gefâss- und entzündlicher Veränderung leicht erklärt, ebenso wie es begreiflich ist, dass stărkere Blutgefässe dem entstehenden Zuge gegenüber länger widerstandsfälig bleiben. Leider besitze ich jenes interessante Präparat nicht mehr, so dass ich nicht im Stande bin, Abbildungen und Einzelheiten beizubringen. Immerhin lohnt es sich vielleicht, solehe Veränderungen absichtlich herbeizuführen, in gleicher Weise, wie uns van Gieson bekanntlich experimentell gezeigt hat, dass manche eigenthümliche Dislocationen der grauen Substanz durch künstlichen Druck auf die Medula spinalis herbeigefübrt werden können, dié man früher für angeborene oder während des Lebens erworbene hielt, - der Verfasser dieser Zeilen nicht ganz ausgeschlossen. In welcher Weise in dem Freudweiler'schen Falle die beschriebene Veränderung herbeigeführt worden ist, vermag ich natürlich nicht anzugeben; ich wollte nur auf eine Möglichkeit. der Entstehung sonst ganz unverständlicher Hohlräume und „Gliome ${ }^{\varkappa}$ binweisen.

3.

\section{Zu Wolff's Entgegnung}

in diesem Archiv, Bd. 157, Heft 1, S. 194

von

Ferdinand Bähr.

Es ist richtig, Wolff hat allen denen, welche an seinen Ansichten etwas auszusetzen hatten, Abfertigungen zu Theil werden lassen, aber Abfertigungen, namentlich Wolf $f^{\circ}$ sche, sind keine Widerlegungen. Auch hier bewegt sich Wolff wieder in einer Abfertigung, während es ibm doch ein Leichtes sein müsste, mich zu widerlegen, zu widerlegen mit Beweisen, nicht mit Behauptungen und zusammenhanglosen Oitaten, deren Inhalts-Berechtigung zudem dabinsteht.

So bleibt denn leider neben Anderem dieser "letzte Strohbalm" und er wird Wolff noch länger Gelegenbeit geben, zur Beseitigung seine Mittelchen anzuwenden. 